\title{
HUNGARIAN ECONOMIC POLICY BETWEEN 1989 AND 2019
}

Péter Ákos Bod

\begin{abstract}
The stirring social and political events of the change of regime in 1989/1990 and the subsequent periods have had an extremely powerful effect on the transformation of the Hungarian economy. Hungary entered the European order of market economy with partial monetisation, oversized industry, and neglected infrastructure. The economic policy thinking was dominated by worries about external indebtedness and by the intention of definitively joining the western political system, while closing the gap between the income levels of Hungary and the developed West was in the focus of social expectations. The establishment of the institutional system of market economy and getting into the western order have eventually been successfully accomplished, yet income convergence has proved to be uneven and slow, which has led to widespread frustration. The financial crisis of 2008 exposed the risks arising from high degree of trade and financial openness. As a joint result of unorthodox economic policies of the subsequent period and beneficial external conditions, Hungary's external exposure has decreased to date. However, growing centralisation and the government's pro-sovereignty policy will increase the frequency of conflicts with EU institutions. Despite economic policies to accelerate convergence, Hungary's middle-income status has become permanent, strengthening external and internal migration and increasing regional tensions in the country. The new phenomena of product and labour markets, as well as new technological trends will put Hungarian economic policy to test. Besides, adjustment tasks emanate from ongoing complex European policy changes.
\end{abstract}

JEL codes: E02, E44, E60, F15, 43

Keywords: change of regime, institutions of the market economy, cooperation within CMEA, two-tier banking system, European integration, macroeconomic stabilisation, labour productivity 


\section{HUNGARY'S PLACE: ON THE PERIPHERY OF EUROPE}

\subsection{Continuity in the midst of changes: moderate development, higher ambition}

The economic circumstances in Hungary have changed tremendously over three decades. In order to interpret them, we must leave the world of economic facts and data, acknowledging the importance of successive political changes. At the time of writing, even the map of Europe is different from that at the beginning of the period. In 1989, People's Republic of Hungary was bordered by five neighbouring countries, three of which (Czechoslovakia, Yugoslavia and the Soviet Union) were to cease to exist soon. In those days, Hungary was a member of the Warsaw Pact, an anti-NATO military association, and the CMEA, a production specialisation organisation run by the Soviet Union. Soon after the political shift, both organisations were dissolved. Since then, Hungary has been part of the western order of alliances and the European integration.

The development of all Central and Eastern European countries has been extremely powerfully determined by foreign politics and geopolitics. Yet, in social and economic aspects, the region had not become a homogeneous bloc even in the period of the Cold War. After 1990, Central and Eastern European nations chose considerably different paths in economic and social policy, despite the fact that all of them had undergone intense institutional harmonisation as EU candidates and then as members. Still, Estonia, for instance, is markedly different from Romania, or Slovenia from Hungary. If one realizes the developmental and structural differences and national features, it is easier to understand the paths taken by these countries and to predict the possible responses to the challenges of the present.

The path that one particular country has covered should not be evaluated on the basis of its own past, but rather on the basis of an objective benchmark: the performance of other nations. However, it is not evident which framework is adequate for the assessment of the Hungarian economic path and economic policy practice, beyond the fact that among other nations, Hungary is referred to as a post-communist society, a transitional country, and a former planned economy since the turn of 1989/1990. True, but the terms above also apply to the former German Democratic Republic, Serbia or Poland, yet only the last name is relevant for the interpretation of the three-decade-long path of the Hungarian economic policy. The benchmark cannot be chosen arbitrarily, nor can it be deduced exclusively from objective indicators: the sentiments of the society should also be considered. Traditionally, the Hungarian public opinion has considered Austria or Germany as a benchmark. Even today, Hungarians hesitate to compare their country to Romania, though based on economic development and the leeway in 
economic policy, it would be more relevant than using the historically understandable but unrealistic Austrian benchmark.

Currently, based on the human development indicators (HDI) and macroeconomic data, market analysts and international organisations classify Hungary as a high HDI nation, an upper-medium income state, and an emerging economy. In geopolitical sense, the country belongs to the periphery of Europe. In this study, we accept the aforementioned categories and apply them to the three-decade-long path.

\subsection{Long lasting legacies of economic history}

Compared to the then core countries, Hungarian capitalism had emerged fairly late. However, it is important to see that the Hungarian economy was not considered to be underdeveloped in the period of the emergence of capitalism. In the 19th century, Hungary's development level differed considerably from that of Western Europe, but the chances of convergence were not nil. The credit institution sector, the stock exchange, the integrated rail traffic system, the land and real property cadastre, commercial and financial law and other important institutions of the capitalist order were well established even by the European standards of the era. A larger entity, the Austro-Hungarian Monarchy, served as a framework for market development. True, in terms of economic advancement, the Monarchy was lagging one step behind the western part of Europe, and its political evolution was also different in many respects, for example, it did not take part in colonisation overseas. At the same time, regarding access to technology, capital and market, the Monarchy proved to be an inspiring integration framework for the Hungarian economy. Although the income level of the Hungarian Kingdom reached only two-thirds of the more developed provinces of the Monarchy, the economy was growing fast. Hungary has never had so high growth advantage over western neighbours since then, especially in the 30 years examined here.

The "golden period" was closed for good by the new configuration of European power relations in 1918. Between the two world wars, Hungary suffered social and economic shocks but regained politically sovereignty. The economy was relatively well industrialised, but it strongly depended on German, Austrian and Italian markets, for political and structural reasons. After the Second World War, Hungary was forced again to follow an inescapable path, and its sovereignty was limited, this time by the USSR. The path of the country's reconstruction and modernisation was again restrained by external forces: Hungary drifted into the Eastern bloc. The economic structure was determined by the single-party, repressive political system and by decades of forced industrialisation based on the logic of the Cold War. 
These antecedents left behind some consequence for the present. One particular point we should pay special attention to is a phenomenon that still permeates Hungarian social and economic policy: the desire to catch up with the West, and the obsession to compare things to those of Austria and Germany. Historically, it is understandable, but it fuels the permanent frustration of the Hungarian society. While Eastern Europe, including Hungary, had previously became part of the sphere of interest of the Soviet Union, an economically less developed, militarised power after 1945, Western European states had meanwhile chosen the path of integration, overcoming national divisions. During the 1960 s and 7os, Austria and Germany reached an income level that surpassed even the rapidly growing West European average. Thus, the development gap between them and Hungary further increased in the second half of the 2oth century. The former are, by global standards, core countries, while today's Hungary is a peripheral country, just like it was in previous periods of economic history.

In economic policy, particularly difficult challenges have arisen since the middle of the 30-year-long period discussed here as the Hungarian state has had to cope with specific problems caused by the peripheral position and being in emerging market status, but meanwhile at the same time Hungary has had to exploit the opportunities and fulfil the obligations deriving from the country's membership of EU, a socially and economically advanced entity.

\section{ECONOMIC POLICIES DURING THE CHANGE OF REGIME}

\subsection{Orderly political transition in 1989/1990 - on the verge of economic collapse}

In the region, the political sea-change of 1989-90 was directly caused by sudden shifts in geopolitical circumstances, but the state of the economy also significantly affected the fate of the incumbent political regime and the manner of its change. By 1989, the state party (the Hungarian Socialist Workers' Party) had realised that the long-standing accumulated structural problems, in particular the acute financial difficulties, could not be solved within the existing institutional and political framework, nor by means of customary reform/adjustment techniques. At the same time, the establishment party did not have the legitimacy to initiate a radical change. By the end of 1989, even the international financial liquidity of Hungary had become uncertain in the eyes of creditors and capital market partners. Hungary had been a member of and in a credit relationship with the IMF since 1982, but the relationship was badly affected by the disclosure, at the 
end of 1989, of data falsification ("misreporting") which had been going on since Hungary's entry into the organisation.

The communist regime was driven to accept the constitutional claims of the unified opposition, organized into a "round table" as the financial collapse seemed to be so close. Free elections were held in the spring of 1990. At the time, following the break-up of the state party, the larger successor (the Hungarian Socialist Party) seemed to have a chance to win the relatively strongest position in the new Parliament. However, the political dynamics turned out to be different: the Socialists eventually obtained only $10 \%$ of the parliamentary seats, while there was a close contest for the pole position between the centre-right MDF (Hungarian Democratic Forum) and the politically left-liberal SZDSZ (Alliance of Free Democrats). In April 1990, the Hungarian Democratic Forum, having won the relative majority, managed to form a government in coalition with the Independent Smallholders' Party and the Christian Democrats, while the parliamentary opposition consisted of the Alliance of Free Democrats, the then liberal-alternative FIDESZ (Alliance of Young Democrats) and the Hungarian Socialist Party. Perhaps, it was in Hungary where the change of the political regime took place in the most orderly way in the whole region, putting aside the special case of Germany where the Eastern provinces got integrated into the West-German political, legal and economic system fast, and consequently, they became part of the European Economic Community without transition.

The Hungarian change of regime seemed to be successful not only compared to the increasing number of crises which suddenly developed in the region. The efficiency of the constitutional order was indicated by the regularity of the fouryearly election cycles and the organised manner of appointing new Prime Ministers, either because of the death of the PM in office (József Antall, †1993) or for political reasons (Péter Medgyessy, 2004; Ferenc Gyurcsány, 2009). On the whole, the Hungarian constitutional order was an advantage for economic development.

However, the same cannot be said of the economic structure that democratic Hungary inherited in 1990. Despite favourable international opinion and the expectations of the Hungarian public, it did not prove to be better than the economic structures in other countries of the region. The structural problems had been partly known to the decision-makers, and, to some extent, to the general public. Still other aspects were being revealed gradually during the process of regime change. One fact was known: although the economic policy stage of "the country of iron and steel" dates back to the first half of state socialism, that is to the 1950s, yet despite all subsequent reforms, the heavy industry, heavy chemistry, mining and the armaments industry which were left behind remained massively oversized. Such a legacy would have called for a kind of regional and sectoral crisis management exercise that was applied in Western Europe in the 1970s, de- 
manding vast resources.. However, similar financial resources were not available for this purpose after 1990 in Hungary. In addition, there was another general heritage of the same gravity: the socialist industry and agriculture had been dominated by low or medium-quality production, with limited marketability.

The general gap in quality and marketability was partly due to the prior international integration position of Hungary. From the 196os on, the intra-state specialisation within the so-called Council of Mutual Economic Assistance (CMEA) had been based on political logic, rather than on the principles of comparative advantages, and this fact distorted the product range of the Hungarian machine industry, food industry, light industry, pharmaceuticals production and other sectors employing a large number of people. After the dissolution of the CMEA in 1990, the basis for the existence of various product cultures concerned simply disappeared. Products manufactured in compliance with Eastern standards and demand could not be economically placed on other external markets, while domestic demand was not enough to maintain capacities.

As far as quality problem is concerned, the roots could be found in the whole political and economic system. Already from the 1950s, operational disruptions indicated that the large-scale nationalised industry may have been suitable for manufacturing homogeneous products of mediocre quality in large volume, but it prevented flexibility, innovation and competitiveness. In Soviet-Russian context, promotion of mass production may have had a modernising effect, but this kind of production culture was a step backwards for Hungary. Meanwhile, in the light of "economic miracles" taking place in Western Europe, it became gradually apparent in Hungary and in other relatively developed Socialist countries that centralised planning was a kind of dead end.

The "New Economic Mechanism (NEM)" of 1968, which extended state owned enterprise independence from state bureaucracy, was a reaction to the realisation above. NEM achieved some results: corporate management became more flexible and sensitive to demand. The symbiosis of big state-owned companies and small entrepreneurial units, something that later the Chinese introduced into their governance models, led to the emergence of unusual hybrid forms, which became common mainly in some sectors of agriculture and services - as long as the big firms existed. . However, at the very beginning of the 1990s, when the big stateowned companies went bankrupt, were privatized or cut into smaller companies, the small proto-enterprises living in symbiosis with them often disappeared.

Hungarian industrial production stopped growing already at the last stage of the planned economy due to the combined effect of stricter external markets and the deterioration of competitiveness. As a reaction, the regime intended to give special treatment to the fifty largest (and as such, politically sensitive) companies, as an early manifestation of the "too-big-to-fail" principle. After the change 
of regime, however, there was neither funding, nor intention to give preferential treatment to such a large part of the domestic economy. Due to international obligations, it was not even possible.

Yet, in the light of the dynamics of Vietnam, China, both acting cautiously in developing market conditions, on the one hand, , and experiencing the deep drop in industrial production after 1990 in Hungary, on the other hand, the obvious question arises: would it not have been a better solution to give time for domestic enterprises for preparation and to slow down the opening up the markets? In order to answer this question, the macroeconomic relations need to be examined: the indebtedness of the state, the structural problems of the economy, as well as the constraining influence of economic theory and economic ideology of the era.

\subsection{When previous mistakes and debts surface}

The most serious problem that rendered the return to the market economy system more difficult and was in the focus of public debate in 1990 was the severe government forex debt of Hungary, mainly to foreign creditors. In the case of the People's Republic of Hungary, indebtedness in the currency of other countries (the "original sin" in the literature of development economics) had mostly been due to the fact that domestic saving was never enough to finance the twin deficits (the continuous government budget deficit and the current account deficit).

The foreign trade deficit of the 1970s and 1980s was financed first by trade loans, then gradually by international bank loans and by issuing foreign currency bonds. In the late 1970s, however, the financial market conditions suddenly became difficult, which urged the Hungarian Communist party leadership to join the International Monetary Fund and the World Bank. By accepting the conditions of membership and promising further reforms, Hungary managed to receive additional resources from these organisations from 1982. At the same time, the process of debt accumulation continued.

Prior to the free elections in 1990, the Communist government took measures to increase its popularity. For example, the foreign exchange touristic quota, which a lot of citizens used for the purpose of private import in the world of import restrictions, was raised. As a result, the foreign reserves of the country fell back to a critical level. By the time of the elections held in the spring of 1990, Hungary's total foreign debt amounted to 16 billion euros (in present terms), compared to which the amount of foreign exchange reserves in convertible foreign currencies was merely EUR 875 million. This quantity was definitely not enough, given that the stock of short-term (within one year) foreign currency debt was three times as high as the amount of the reserves. Consequently, the Antall government taking office in 1990 had to rely heavily on the cooperation with the IMF and needed the 
confidence of the international capital market very much. All this considerably restricted the leeway of the first freely elected government in economic policy aspects.

It is understandable that given these difficulties in the beginning, the government's economic policy stance of punctual debt serving (aiming to avoid default) was hotly debated in public. In connection with external debt, the public has been and still is hostage to false narratives. Some people still condemn the Németh government (1988-89) and later the Antall government (1990-1993), for not copying the still ongoing restructuring negotiations of Poland, a country that declared default in 1982; in spite of the fact that both governments managed totally different legal and material conditions. Others expected that the West would write off debts, taking into account the historical merits of Hungary. Another urban legend held that Hungary could have received debt reductions upon request. All these speculations were unfounded. Despite all the encouragement and general promises from western political circles, it became obvious soon that the countries of the region could not expect any comprehensive debt relief. The former planned economies, which were in a very different situation, had to find individual strategies tailored to their own circumstances. Meanwhile, the number of transition countries multiplied due to the disintegration of the Soviet Union, and thus new players appeared on the scene. In order to facilitate their transition, the international community established an international development bank (EBRD) and increased the activity of the IMF in the area. In the case of Hungary, the international community did not even consider debt relief. The government was eager to avoid any manoeuvre that may have triggered sovereign default as such an event would have posed a serious risk to the initially successful and promising transition.

The misunderstandings and unfounded hopes hindered the debt management work of the Antall government, as they fed rumours about imminent debt rescheduling of Hungary, an otherwise solvent country, and the capital markets might have interpreted these noises as a sign of poor willingness to pay. Eventually, the Hungarian strategy of timely debt service turned out to be successful in the medium term. The government managed to tap foreign funds with longer duration and at lower interest rates, mobilized privatisation receipts and foreign direct investment (FDI), and this way the structure of the country's external debt changed rapidly. In the meantime, the saving positions of Hungarian households improved significantly; the share of domestic saving, intermediated through the banking sector, increased in financing the budget deficit. At the time of the next parliamentary elections in 1994, foreign currency reserves of the National Bank of Hungary were already high enough to assuage any concern that financial markets might have had about the change of government: international reserves reached the level of EUR 5.4 billion, while short-term foreign debt remained under EUR 2 billion. 
The export capability of the economy was improving, current account concerns were easing. Over a decade, the country managed to overcome the hard period marked by external debt and internal public debt. So much so that, in the early 200os, at the time when the adoption of the euro was being considered for the first time, the only Maastricht criterion Hungary could have complied with was the public debt to GDP ratio (then 52\%). The significance of this can also be evaluated in the light of the fact that in 2018, this indicator was well over $70 \%$, in spite of the incoming EU transfers that amounted to several billions of euros year in, year out, unburdening the state budget.

At the same time, serious prior neglects and structural rigidities surfaced in the first years of the regime change. The former Reform-Socialist regime (1968-1989) relied on simulated, and not real, market competition, promising more rational and economical use of resources than under classical central planning, but in 1990 it turned out that the heritage of the reformed Hungarian economy in terms of labour productivity, energy intensity, and capital efficiency was not significantly better than the legacy of Communist Czechoslovakia with strict central planning or the Polish economy that had been hit by several crises. At the moment of the opening of the market, the energy content of production was several times higher in the CEE region than in Western Europe. The somewhat better situation of Hungary was only due to the fact that the share of heavy industry had become smaller in Hungary by then. Owing to the termination of public subsidies and the transition to world market prices, suddenly energy became expensive for enterprises after 1990, and higher prices revealed the uncompetitiveness of several sectors. Despite the low wages in the region, given the poor efficiency and productivity of many state-owned and newly privatised companies, the competitive position of the new democracies, and Hungary was no exception, turned out to be worse than expected.

The banking sector was one of the areas which failed to meet the expectations. In this field, Hungarian Reform-Socialism was more open than the countries of the region (except perhaps for Yugoslavia): in Hungary, the first joint-venture banks or completely foreign owned banks were allowed to appear in the 1980s. Prompted by the IMF and the World Bank, Hungary established (or more accurately: restored) two-tier banking system, and allowed the establishing of commercial banks already in 1986. The troublesome process of the restoration of the two-tier banking system will not be elaborated in this study, but some important economic policy implications should be mentioned here.

The troubles of the financial sector mainly derived from the four-decade-long planned economy system. The problems included the lack of sufficient expertise both on the part of banks and of clients, as well as the rudimentary and unstable nature of the legal framework. As a consequence, bankers tended to ignore 
prudential aspects, and clients borrowed unthoughtfully. All this characterised mainly the initial years (1986-89). However, in a short time, due to the combined effect of the market opening and the start of the privatisation process, the main problem was not the excessive funding allocation, but rather the fast deterioration of the quality of the existing loans. The foreign and joint-venture banks, established in the framework of "greenfield" investment projects, canvassed their clients deliberately, but the state-owned credit institutions inherited their clientele, including mainly companies in public ownership, which got into trouble one after another owing to the loss of their principal markets and through mismanagement. Loans to such clients tended to become nonperforming, which would have undermined the profitability and later the solvency of the banks even if they had been established with enough capital in the previous years. But they were not. Soon, banks which depended on clients with deteriorating situation had to face problems themselves.

Decline in the lending capacity of Hungarian banking sector added to the headaches of economic policy makers because it deepened the unfolding recession. The volume index of the GDP shrank from 1990 on for four consecutive years. It reached its trough in 1993 with 82\% of the level of 1989. Hungary's cumulative contraction was about the same as that of Czechoslovakia and Poland. In the latter case, the recession began earlier and ended sooner. Among nations east and south of Hungary, transitional recession was even deeper, and it took more time to return to the GDP level achieved before the change of regime. The return to the base level took nearly a decade in Hungary - which is astounding. The surprisingly intense output shrinkage is attributed to several factors. One of them is the fluctuating performance of the credit sector, which definitely failed to meet the expectations. The negative effect of the credit crunch on economy was even made worse because of the end of providing public subsidies. On the other hand, the inflow of foreign direct investment, which was the highest in Hungary in the region, helped the economy. It is, however, of note that at that time the CEE region, including Hungary, did not receive EU transfers unlike after 2004t, and in particular since the opening of the seven-year-long EU financial frameworks in 2007. The mounting problems of the banking sector indirectly influenced later public deficit and debt figures. In order to avoid the bankruptcy of undercapitalised stateowned banks, they had to be recapitalised: the Hungarian government pumped budgetary funds into state-owned credit institutions between 1991 and 1994 to restore capital adequacy ratios under the so-called "bank consolidation". For this purpose, a substantial amount of debt instruments had to be issued, which increased the official budget deficit and the stock of government debt. Despite the fact that these transactions did not increase macroeconomic demand, and budget statistics practices later acknowledged similar transactions as off-budget changes, in the 3-4 critical years of the change of regime, the transactions of the "debtor 
and bank consolidation" appeared in the macroeconomic indicators of Hungary, significantly deteriorating them.

Similarly, to the situation described above, banks have been bailed out and recapitalised in the developed world on several occasions since 2008. Yet, back in the 1990s, state intervention to maintain the operability of the financial intermediation was a more controversial issue. One of the reasons why bail-out of banks was less accepted in the 1990s than after the Great Crisis is the influence of the economics and economic policy mainstream' that in was much stronger at the time of transition.

\section{NARROW ELBOWROOM FOR NATION STATES AT THE PEAK OF GLOBALISATION}

\subsection{Reasons for the bigger-than-expected output decline}

Everywhere in the CEE region, return to market economy proved to be more difficult than predicted by preliminary analyses, not to mention the expectations of the public. In the case of Hungary and other nations of Central and Eastern Europe, the historical detour lasted for four decades, while for the Russian society, for seventy years. In the latter case, there were practically no adults alive who had personal experience with market economy. Moreover, the economic system to which the societies concerned returned after a several-decade-long hiatus was very different from the capitalism of the past. In the period prior to the change of regime, only those employed in foreign trade or in banking relationship with western partners, or those who studied or worked abroad could be familiar with the business life of the modern era. The number of such people was insignificant in the Soviet Union, and it was low even in the relatively open socialist countries. The members of the foreign diaspora who returned to their home countries after the democratic change were those who could have brought home up-to-date market knowledge or other kind of social capital.

In the period prior to the change of regime, Hungary was in a relatively favourable position regarding external openness, in particular due to the western business relations of its state-owned and (a few) private companies. In spite of this fact, the circle of widely travelled people remained limited. The Hungarian diaspora played only a tertiary role in the preparation and implementation of the change of regime, particularly in comparison with Poland. Based on their experience gained in the decades of reform socialism, the Hungarian economic agents knew somewhat more about monetary and commodity relations than the citizens 
of countries with a prior rigid planned economy, but this advantage proved to be very relative. The "New Mechanism" of 1968 could not properly prepare Hungarian society for real market operation, as the simulated market relations of the public sector and the particular ways and means of the second (or black) economy were very different from the norms of the modern and already completely globalised market economy.

As in the case of Czechoslovakia or Poland, a significant part of the Hungarian elite that implemented the change of regime was recruited from intellectuals and from among middle and senior corporate management who decided to take part in public life. These social groups were more familiar with the conditions of the new era and the demands of the external world but, of course, they were not fully prepared to solve the complex problems of the age. Compared to western countries with a different development path, actors with a labour union, civil society organisation or private business background were underrepresented in politics. Consequently, as far as political parties were concerned, there were no experienced second and third lines. Even on the central and local levels of state administration, there was a shortage of officials who could meet the requirements of modern civil service.

In terms of the aspects listed above, Hungary was not lagging behind others, but did not have an advantage either. The professionality and efficiency of public decision-making obviously did not meet the unrealistically high expectations of the society. Public affairs had been politicised from the beginning, while the political class was divided by sharp political, cultural and emotional lines. As far as the democratic turn was concerned, all this threw cold water on the hopes of a significant part of the society very soon.

It is noteworthy, however, that the western community entertained excessive optimism at the time. The IMF, the European Commission, and the international organisations predicted that the transition would be much easier that it actually was. The $\mathrm{V}_{4}$ (later $\mathrm{V}_{3}$ ) countries lost one fifth of their production in the first few years of the transition. Due to the greenfield investments, de novo private companies, and successfully privatised corporations and cooperatives, a new production structure was born, though more slowly than expected. The transition of agriculture took even more time. When preparing its Polish and Hungarian loan programmes in 1990, the International Monetary Fund calculated with a transitional recession costing a few percent of GDP, but the contraction in the CEE region turned out to be triple rather than double of the percentage expected.

Let us face it that the economic theory of transition has not been able to give a single explanation for the reasons of the higher-than-expected transition contraction to date. Some experts query whether the official statistical system measured the GDP prior to the transition to market economy well and whether statistics 
registered the production and income processes taking place in the course of the fast transition properly. There is no doubt that sufficiently reliable and timely national economic statistics have been available only since 1995 .

As far as the case of Hungary is concerned, the deep transitional downturn of the early 1990 os was influenced by a factor that also contributed to the similarly serous GDP fall ( $7 \%$ in one year) in 2009: the high level of external openness of the economy. In a highly open economy, growth can be much faster than the European average during boom years, but the contraction can be similarly deeper than the average during economic downturn.

\subsection{External economic policy advice}

Although external openness is a plausible reason for above-average growth and volatility in the Hungarian case, the question arises: Why did the economy not display a growth after the transition crisis, at the time of favourable foreign boom as robust as the South Korean economy in the 1960s? In order to answer this question, we should deal with the economic orthodoxy of the 1990s and the consequences of the so-call neoliberal economic policy.

The "ten commandments" for economic policy known as the Washington Consensus was essentially addressed to Latin American countries with populist tendencies (Willamson, 1989). Yet, all former planned economies received the same "Privatise, deregulate and liberalise!" message from the international organisations, western governments and the majority of the academic community in the 1990 . Most external experts recommended determined and fast transition, though the shock therapy was known to cause seriously negative social impact. Still, it was considered to be better than the gradual, scheduled transition. As J. Sacks, a renowned advocate of shock therapy, put it: the formula for success in the transition region is that the West should open up markets, provide (if required) debt relief and financial support to "new democracies", which should immediately adopt the developed western institutional system in return (Sacks, 1990).

In fact, none of the above conditions were in fact fulfilled. The western governments overrated the technological level of the Soviet Union and other planned economies and saw no reason to offer them serious financial support on top of IMF loans. After the democratic turn, eastern companies paying low wages were thought to be price competitive. For this reason, and remembering previous cases of East European state dumping, the West did not want to establish an asymmetric foreign trade regime that would have favoured the new democracies.

The wrong assessment of the situation described above was reinforced by the ideology of the age. At the beginning of the 1990s, even temporary preservation 
of public property, any form of public restructuring and market protection was almost unanimously rejected, not only by governments on the right in the European political scene but also by social democratic governments. The fast handover or, from the perspective of the other side, the immediate adoption of successful western legal and market institutions seemed to be enough, to make new market economies a success. Although some of us considered it to be naivety, a lot of experts seriously believed that the mere adoption of the institutional system was enough. Market fundamentalists believed that mutual opening of markets, the definite removal of obstacles to entrepreneurship and adoption of the western institution together guarantee economic success.

All this characterised the public opinion in the short period prior to the great disappointment after the unification of Germany in late 1990 and the chaos caused by the Russian economic transition in 1991 and 1992. In a short time, the unexpectedly heavy heritage of former planned economies, a drag on the regime change, and the real depth of the crisis started to surface. In his Nobel Price acceptance speech, $D$. North underlines that although formal economic institutions could be easily adopted, the transformation of non-formal institutions (customs, social norms, practices) took a long time. He admitted that privatisation was not a panacea for poor economic activity (North, 1993).

True, the policy of the IMF changed over time, the loan conditionality was not as rigid and did not adhere to a single standard anymore from the late 1990 on, partly due to the shifts in economic theory and thanks to the lessons learnt and popularized by the transitology literature which interpreted the specificities of the region in scholarly manner. Yet, it took time for the world to understand the complexity of the tasks of the regime change.

\subsection{A crisis period, growth in a new structure, and the emergence of a dual economy}

As mentioned, the statistically measured output of the Hungarian economy dropped to its lowest point in 1993, and it took years for the economy after 1989 to return to the path of lasting growth. It is difficult to compare Hungary with similar countries of the region, as the indices of the early years are slightly uncertain. Since then, the statistical order has considerably changed, including FISIM, which was not accounted before 1995. The official annual volume data of the Central Statistics Office and the indices calculated on the basis of such data reveal the depth of the crisis. Changes in the real GDP based on the year 1989: 1990: $-3.5 \%$; 1991: $-12.1 \%$, 1992: $-3.0 \%$, 1993: - o.8\%; 1994: +3.1\%, 1995: +1.5\%, 1996: +0.2\%.

In the light of the above, the index started growing in the middle of the fourth 
year, in 1993. Economic growth reappeared in a quite different structure from the earlier. However, owing to austerity measures, it ran out of steam from the second half of 1995 to 1996 . Anyway, in 1996, the GDP was still 15\% below the level of 1989. These seven years should be considered to be the period of the transition crisis to be followed by a new economic period. The division applied in this study (1990-1996; 1997-) is different from those that follow political cycles, which links the new period to 1994 (election year) or the macroeconomic correction of 1995 (the "Bokros Package"). Still, the years 1990 to 1996 should be treated as belonging to one period, for the characteristics of the structure of the economy, institution building phase and economic cycle.

The assessment of the stabilisation package of 1995 has remained controversial. Some experts praise its balancing effects, while others criticise it for slowing down the emerging growth. There are also some who rather object to the neoliberal ideology associated with it, or refuse it because of its serious unfavourable social (and demographic) effects. The afterlife of the package is interesting, as well: in international literature, it is often referred to as a turning point and the start of the period of growth, even if it is not supported by output and investment data. But the elements of the package (currency devaluation, reduction of social spending, and the restart of privatisation) are measures which are easy to interpret internationally. The left-wing coalition in office (1994-1998, 2002-2010) tended to regard the measures of 1995 as by and large correct, and the Left considered the package to be the proof and symbol of its pro-market attitude. On the other hand, Fidesz, an opposition party at that time, defined its own economic policy against the neoliberal direction embodied by the Bokros Package, especially after 2010.

It is worth setting aside the question whether the neoliberal economic policy trend existed at all in Hungary in earnest or it was only talked about. In this study we claim that macroeconomic stabilisation of 1995 was part of the first phase, irrespective of political cycle. Certain fiscal adjustment measures would have occurred anyway, perhaps in a different form, under a different schedule and on a different ideological basis. This assumption is also supported by the economic trends in other transition countries. The transition crisis of the 1990s typically consisted of two stages in the CEE region: it started with a fall in general production, while equilibrium indicators deteriorated: the budget deficit increased owing to a decrease in revenues and the surge of one-off expenditure items triggered by the transformation. Inflation accelerated, as well. Consequently, in the second part of the transition crisis, macroeconomic stabilisation as an integral part of it, became necessary.

However, its form was different in every country. For example, in the Polish transition, it was not the state budget that became a critical issue, as over the years of struggle, the welfare role of the state had decreased. Both public expenditures and 
the current account deficit were lower than in Hungary, imbalance manifested itself rather in the runaway inflation. In 1993, the Polish złoty got redenominated by cutting four zeroes. In Hungary, the inflation was never as high as in Poland in that period. The Hungarian inflation reached its peak in 1991, then a period of disinflation followed until the end of 1994, when the headline rate dropped to $17 \%$. Later, due to the stabilisation package of 1995, the annual consumer price index approached $30 \%$ again, and then has gradually become a one-digit value.

All currency functions of the forint remained preserved during the transition. Yet, it can be stated that price stability as an objective is not as deeply embedded in public awareness as, for example, in the Czech Republic. This is also true for fiscal discipline: the Hungarian budget deficit ratio was higher than in the Czech Republic throughout the whole period examined. The volatility of the Hungarian deficit is especially conspicuous, as it follows the political cycles: the governments closed the election years with a high deficit in the first two decades. One of the implications of this was that the Hungarian state was placed under the EU's excess deficit procedure record long, until 2013. Since 2013, the deficit rate below $3 \%$ of the GDP has been almost the only fix economic indicator, even though the economic cycle has markedly changed. For a specific political reason: the government tries to keep the deficit-to-GDP ratio below the EU limit so as to hold off the European Commission.

Considering the period between 1990 and 1996 as a single phase is also justified by the fact that the bulk of the radical change to the economic structure of Hungary took place in this period. The foreign literature regarded the Hungarian macroeconomic transition as gradual compared to the transition in the members of the Visegrád Group, the Baltic countries or Russia, accepting other governments' declarations about their radical transition. But microeconomic data paint a different picture. Hungary excelled at the speed of structural transformation: data related to capital inflow, entrepreneurship, bankruptcy and liquidation laws, the change of the financial mediatory system, and the increase in labour productivity, it is clear that Hungary was in the forefront of structural and institutional transformation. In other countries, the modernisation of economic life happened with more compromise and hidden mistakes. For example, in the late 1990s, in the Czech economy, the harmful by-effects of the voucher privatization scheme, especially the weaknesses of corporate governance, which played a role in the recession of 1997-98, came to the surface. In the early 200os, Poland had to face inherited industry structural rigidities, similar to those that Hungary had already done away with a decade earlier. In the late 1990s, Slovakia was also hit by a belated crisis due to privatisation policy or rather the lack of it.

In comparison with the examples listed above, the structural modernisation of the Hungarian economy can be considered to be the most powerful. At the same 
time, Hungary was the first state where the duality of the economy became clearly observable. On the one hand, there is a well-capitalised sector, dominated by foreign companies. On the other hand, the second sector is in Hungarian private ownership. The remaining companies are owned by the state. In the latter two categories (local small and publicly owned), labour productivity and capital efficiency are much lower. In fact, instead of duality, we should talk about an economy consisting of simultaneously operating fragments.

\section{ECONOMIC POLICY ROOM OF MANOEUVRE OF A MIDDLE-INCOME COUNTRY WITH SHARED SOVEREIGNTY}

\subsection{Privatisation and capital import as structural policy}

Following the powerful shocks of the first decade, the Hungarian economy grew fast compared to its own potential. From 1997 to 2006, the GDP increased faster than the EU average, therefore Hungary moved closer to the countries considered to be the comparison standards. However, it was known that the growth rate was pushed above the natural growth rate by the indebtedness of the central government, local governments, and households. Nevertheless, Hungary remained a middle-income economy, one with increased variance of its constituting factors behind the national statistical average.

The national economy average obscures the aforementioned duality in economic structure, which the Hungarian public knows as the problem of multinational companies (despite the fact that the companies concerned may be businesses in foreign national ownership: German or Japanese car manufacturers, American electronics companies, a Swiss food industry concern or a Belgian bank). The so-called duality problem is due to the fact that intensive international capital flows enlarged the activity and income gap between the central part of the country and the geographically (but rather infrastructurally) more remote regions of Hungary.

This fact would have required strong regional development policy and the consideration of the regional aspect in the distribution of public resources. Still, the first governments had not had serious financial power to do that, until the EU development funds were multiplied after 2007. Regional development as an economic policy area was paid more attention temporarily when the authorities had to deal with the new nomenclature of territorial division (NUTS) in the framework of the preparation for the accession to the EU. After this period, political interest in this area decreased, then the regional aspect was neglected altogether owing to the increasingly centralised character of economic policy. A ministry for regions 
and regional development has been absent in the structure of government for a long time. The lack of professional government bodies with regional remit cannot be made up for by ad hoc Commissioners of the Prime Minister or by political promises about local developments made prior to the elections.

On the other hand, one issue is always subject to the discourse about the economy and economic policy: the fate of small and medium-sized enterprises in Hungarian ownership. The weak job creation potential, the insufficient investment activity, underdeveloped banking relations and frequent shortcomings in management in the SME sector has been a complex set of problem to date. These are not specifically Hungarian, either: being medium-developed asks for an for appropriate policy tailored to the special conditions of this sector. The effort to create such policy has always been present in government programmes: privatisation loan, business starting loan facilities of the first period right after 1990; support to supplier programmes to ease entry of SMEs to value chain, the cluster concept, promotion of industrial parks, introduction of the cheap-loan Széchenyi Card at the end of the period. Competitiveness of SMEs was, over time, included into the priority purposes of use of the EU funds. Yet, the mediocre effectiveness of these programmes is still apparent even after three decades. The same applies to the implementation of industry or structural policy programmes, initiated time and again.

As far as policy mixes are concerned, western economies tend to have a strong incomes policy. In his respect, Hungary is very different, although such neglect is rather general in the CEE region. The middle-income status is often associated with low and stagnating level of real wages and high corporate profit margin, or, to put is differently, low wage share and high profit share of GDP. Low Hungarian take-home wage rate has existed until recently, aggravating the positions of service-providing and producing SMEs through poor purchasing power of wage earners. Prior to Hungary's accession to the EU, or even until 2011, the expiry of the labour market derogation requested by the older member states, limiting effectively legal employment in the West, the domestic wage rate, a fraction of that of the European average, had not led to the mass migration of Hungarian labour to foreign countries. Until then, the more likely social options to counter depressed domestic wages and salaries were early retirement or sinking into the second (informal) economy. The Hungarian inactivity rate got stuck at a high level until the beginning of the second decade of the transition, in spite of impressive economic growth, which can be identified as a serious economic policy mistake: during the expansion, lasting until 2006, there would have been a good chance of increasing employment activity.

The turn in labour policy after 2010 can also be interpreted as a response to earlier policy mistakes. Its elements included government measures against early retirement, the extension of the public work programme and placing it under the super- 
vision of the Ministry of Interior. Due to the programme, the Hungarian employment data have significantly improved. Concerning real employment, the picture is more complex. One of the promises of the public work programme was that it would give people a chance to return to the world of value-creating work from inactivity. It has not come true yet. The social policy critics of the programme claim that the extension of the institution of public work serves the centralised control of disadvantaged social groups that live without permanent income, mainly in the countryside. It is no coincidence that the 2018 country-specific recommendations of the European Commission include the reorganisation of the public work programme, in order to unlock labour reserves through improving the quality of active labour market policies so that_public workers could return to the genuine labour market.

The regulation of the world of work, the amendments to the Labour Code in 2012 and the reregulation of overtime at the end of 2018, which evoked great social resistance, were reactions to the needs of the economic structure that had been established in the first half of the period analysed in this study: a structure in which technology and capital of western firms are combined with the available qualified, an inexpensive, labour force. Due to the absorption of labour reserves and the acceleration of employment outflow to the West, it is increasingly difficult to maintain the production and growth dynamics within the given structure: this issue will be one of the most difficult challenges of the following years.

\subsection{Spending the EU funds as structural and business cycle policy}

With the advance of the transition, the effect of external constraints has not weakened at all. Nowadays, national economic policy is not limited by the IMF loan conditionality anymore (except in moments when a country's liquidity becomes unstable, like in Hungary, in 2008). It is rather the existence of international conventions and membership in integration arrangements that delimit national structural polices such as aiming at supporting local businesses or developing sectors and areas. Being party to conventions and club memberships can be seen as voluntary self-restraint by the nation state in order to promote its long-term goals. Yet, the government of the day might feel the limitation of its freedom to make decisions at will. In 1996, joining the OECD was an important milestone for Hungarian economic policy. As a result, the companies from OECD members are treated the same way as domestic companies, in return for similarly fair treatment for Hungarian firms abroad. Still, the entry also narrowed down the leeway for structural policies of the nation state.

The candidate status and later the full membership in EU brought about even stricter rules. The convergence policies (earlier: structural policies, later: cohesion 
policies) are shaped jointly by the EU institutions and the governments of the Member States. As far as the implementation is concerned, national institutions are given a relatively free hand. Yet, the huge EU funds with their spending terms and rules of use exert a strong external influence on Hungarian economic policy. Providing direct state aid for domestic firms (potential "national champions") is incompatible with the EU norms, any such attempt will infringe competition rules and the ban on state aid, as the high number of infringement procedures against the Hungarian government indicate. On the other hand, most programmes supporting Hungarian SMEs are compatible with the EU norms. Their successful implementation depends much more on the administrative and planning abilities of the Hungarian institutions than on external legal-institutional factors.

The net amount of funds flowing in from the EU has had (and will have if the size of the funds remains the same) a very powerful effect on the equilibrium indicators of the Hungarian economy. In the second half of the period, the annually absorbed forex funds ( $3 \%$ of the GDP on average) accelerated the dry-up of net foreign debt, strengthened the central budget and stabilised agribusiness incomes at a high level. They considerably increased the aggregate demand, which significantly contributed to closing the negative output gap of the economy, especially after 2008. However, it is still not clear how the EU funds (the programmes of the CAP and the cohesion policy) impact the supply side of the economy and to what degree they will enhance the growth potential in the future.

\subsection{Sovereignty and elbowroom of the government}

Over the three-decade period examined, the financial crisis of 2008 brought a critical turn for Europe and for Hungary, as well. As a result, the wave of globalisation unfolding in the 1980 os slowed down. The possible economic policy paths of the former planned economies had been strongly determined by external conditions in the 1990s, then the simultaneous expansion and deepening of the European integration had much limited the leeway for the governments of small, open market economies - but now the crisis created a new situation. In Hungary, the country's high external exposure came to the surface, forcing the government of the day (Socialists - Liberals) to turn to IMF and the EU for financial support in 2008. However, interestingly, after the short-lived financial crisis, much greater leeway opened up for countries going their own ways.

In fact, the commonplace statement about nation states losing their significance in the globalised world was oversold even before 2008. The dominant private sector of the market economy is certainly closely integrated into the external world, and the private sectors of countries with a smaller internal market have especially high external exposure, but the public sector of a mixed economy is also large and 
is closely tied to local politics. Budgetary expenditures generally amount to half of the GDP in European states. Moreover, most EU transfers run through the states and thus can become the means of economic policy making. Thus, states matter. The degree of freedom of the Member States manifested itself in the financial crisis of 2008 and the Eurozone crisis of 2010. Some European core states, led by Germany, called for financial stabilisation, while other states on the periphery could not take or did not wish to take this path. The self-assessment of the Hungarian economic policy line after 2010 is that is differs knowingly from the orthodoxy of Western European economic policy, referring to its policies as "unorthodox".

The turn for national, unconventional policy line was neither unique, nor surprising. Most success stories in economic development are known to have been born as a result of original strategies, like in the earlier modernisation cases in Asia. Of course, the former success cases cannot be copied elsewhere as they took place at a different development level, in a different cultural context than the one that characterised the Central and Eastern European countries at the historic moment of the regime change. At the end of the 2oth century, none of the CEE countries could have chosen the developmental state modernisation path of Asia. Yet they enjoyed a certain, albeit limited, degree of freedom in the sense that any nation had the opportunity to choose individual adaptation technique to join the globalisation process.

As their attitude to monetary sovereignty shows, even the countries of the relatively homogeneous $V_{4}$ Group followed different strategies: Slovakia joined the Eurozone early, while the other three countries have retained national currency. There are strong business and economic arguments for joining the Eurozone; the counterarguments are rather of monetary policy-related, but the pure political aspect of sovereignty is known to be just as decisive. As the case of the European banking union indicated, whether a country joins it or not cannot be clearly deduced from economic rationality; this is why certain countries (e.g. Romania) wish to join, while other countries (e.g. Hungary) do not: the choice is determined by the specific political considerations of the political parties in power.

\subsection{Unorthodox economic policy path after the crisis}

The content analysis of the Hungarian economic policy practice, which is different from the declarations and official statements of the governments concerned, clearly contains individual features in the successive phases. Such characteristics distinguish the Hungarian practice from the dominant trend (orthodoxy) of the era but also from the actual course of other countries in similar situation. At the same time, general trends are still observable, because the Hungarian practice is influenced by various similar effects. 
This study does not allow a proper overview of the various stages, and particularly the detailed analysis of the policy mixture of successive governments. Otherwise, different stages can be distinguished even within a given political cycle: the determined initial institution-building efforts of the Antall government were motivated by their commitment to the German-inspired social market economy model but from the middle of the election cycle, policy makers were rather bogged down in crisis management due to the evolving structural crisis. Similarly, the Horn government (1994-1998) implemented, after initial hesitation, macro-stabilisation measures and launched extensive privatisation including even public utilities (the majority of the latter were renationalised after 2010), but approaching the elections, it changed course by starting a fiscal expansion. Having regard to the global economic turbulences of 1998, the first Orbán government (1998-2002) started its work with fiscally conservative policy, then in mid-cycle, it negotiated a sharp turn towards supply side measures along with loose fiscal and monetary policy stance.

Such or similar switches between stages have been frequent throughout the whole period. They partly reflect the intention of the political leadership (easing of fiscal policy prior to the elections), while in other cases, they occur as the consequences of external constraints and effects. Such a sharp turn took place in the summer of 2006 when fed up with Hungary's multiple infringements of the Stability and Growth Pact, the European Council put an end to the profligate government policy that had led to high budgetary deficit in Hungary. Tightening and softening of EU rules tended to follow a certain cyclical pattern that sometimes clashed with, other times strengthened the Hungarian business-governmental cycle.

Another external factor of cyclicality in the Hungarian case has been the influx of EU funds. This factor is fairly volatile for technical and administrative reasons; therefore it may cause intense swings in aggregate demand. As far as the contribution of EU funds to the aggregate supply is concerned, there is not enough available information. However, the weakness of the absorptive capacity of the Hungarian economy, phenomena of overpricing in the spending of EU funds, the campaign-like character of the use of convergence funds, and the frequently changing administrative background definitely worsen the efficiency of the use of EU resources.

The period after 2008 facilitated the pursuit of unorthodox economic policies in countries with limited external financial dependence or where restraints eased over time. The latter happened in Hungary, owing to the one-way effect of multiple factors. As for one, foreign trade balance had, by 2009, turned into massive export surplus. After 2007, more and more EU funds flowed into the country, then remittances by Hungarian citizens working abroad also increased significantly. Due to the facts listed above, net foreign debt would have fallen even without 
special measures. The fiscal policy, as well as the monetary policy and banking regulation only intensified the process of lessened external exposure.

After 2010, announcing its policy aim to regain sovereignty, the Hungarian government started looking for new paths also in economic policy making. One of its motives must have been the realisation that the income convergence expectations of a large part of the society had not been met, and the need for security had become stronger. Emphasising national interest and stepping up against the EU institutions, the IMF and the representatives of international capital have proven to be politically successful, even though a major part of the society is aware of the benefits arising from Hungary's EU membership. As the financial crisis and the subsequent harsh years made a lot of people regard the whole process of the regime change as a failure, a critical attitude to the Western socio-economic model can be communicated well to a wide range of social groups.

In the second part of the examined period, the growth and convergence performance of the Hungarian economy was modest within the region. This is despite very favourable international circumstances: historically low international interest rate, improving international terms of trade, considerable transfer income from the European Union, and most of all, the pulling effect of the Central European Area, which is very important for Hungarian export. However, some factors withheld the dynamics. The fact that is especially striking compared to other countries in the area: the income share subtracted by the Hungarian state. The centralisation rate approaches, or in some cases, even exceeds the ratio of advanced continental welfare states, and is much higher than in middle-income European countries.

Economic agents, especially foreign players find the unorthodox economic policy decisions, in particular the ad hoc measures, hard to follow; this is reflected in Hungary's sovereign risk ratings. As the assessment issued by Fitch in the spring of 2018 puts it: questions about the credibility of the economic policy course and the unpredictable measures deteriorate the rating based on model calculations $(\mathrm{BBB}+)$, therefore Hungary's sovereign risk rating is only BBB-. Measures aiming to beef up domestic entrepreneurial class may infringe EU competition law and general EU laws. The European cooperation may take a direction that would open up a wider path for individual national policies, simply accepting the diverse national programmes that emerged after the financial crisis, but European political dynamics may evolve into the very opposite: closer cooperation in taxation policy and social regimes, as well giving growing weight to institutions linked to the Eurozone. Should that happen. economic risks arising from following own national paths. 


\section{CONCLUSIONS}

The radical political changes of 1989/1990 and the similarly turbulent events of 2019 provide a unique timeframe for the whole of Europe, including Hungary. In the light of the above, it is difficult to detect the national characteristics and identify the internal tendencies of the Hungarian economic policy and distinguish the external determining factors which led to the events.

At the beginning of the period, economic policy efforts were directed towards an insufficiently monetised, extensively industrialised economy fighting against various imbalances. At the end of the period, a developed market economy in a much better situation provides the framework for economic policy actions. At the initial stage, the dominant intention was to return irrevocably to the former main markets and to internalize the Western institutional and political system, and all chapters in the policy mix were subordinated to this goal. The informational, institutional and political conditions of economic policy-making have changed very fast: initially, policies had to be defined and implemented in the midst of extreme uncertainty. By now, the Hungarian informational order is mostly compliant with the EU nomenclature and methodology.

by the middle of the first decade of transition, the internal institutional order successfully evolved, private ownership became dominant, and Hungary became convincingly anchored to the West in security and trade policy. Meanwhile, great structural transformations in productive sectors had been accomplished, , production cultures which provided a character to the Hungarian economy in terms of output, export and employment were born by the end of the decade. In the era of a high degree of openness in foreign trade and finances, the dilemma of Hungarian economic policy (growth and/or balance), which seems to be eternal, had lost its previous relevance. For some time, it looked that by being integrated into western value chains and by complying with EU norms and decision-making rules, national economic policy might fade into a secondary risk factor, and there is no reason to question the continuous and perceptible progress of income convergence, so much hoped for by the society.

Yet, one cannot but notice that several old problems still exist. Such problems include the tendency for inflation and budgetary deficit, the long-lasting weakness of the regional and interprofessional mobility of the labour force, the wide social acceptance of, and even the demand for, paternalism. In the years prior to the financial crisis, imbalances developed again. As a result, Hungary, as a member of the OECD and the EU, had to turn to the IMF again after many years; true, being not the only country from the periphery of Europe to do so. By this move, the government had to accept the limitation of its decision-making sovereignty in 
an era when the disturbances in the European project resulted in strengthening national rhetoric and turning to heterodox solutions.

Concerning the operation of Hungary's financial markets, the three decades consisted of various sub-periods and processes were interrupted by various turning points. Despite having some years of advantage in the beginning over other nations in the CEE region, the Hungarian financial system was unable to avoid shocks, bank failures and scandals in the 1990s. Similarly, to the banking system of other former socialist countries, the majority of the Hungarian financial system also got into foreign ownership. Regarding financial depth, at the end of the period, together with other nations with similar background, Hungary is still lagging behind the EU average, though the banking system has become more shock-proof since the crisis. The dream that Budapest may develop into an outstanding regional financial hub has not been fulfilled. Due to the (also) politically motivated infrastructure development projects and mainly to Hungary's economic-geographical position, the country has a better chance of becoming a logistics centre, instead.

In the absence of well-considered structural programmes with sufficient financial support, the structure of the economy has been formed mainly by EU accession programmes and aid schemes, as well as by capital importing deals. The processes of digitalisation and automation have a powerful endangering and potentially enriching effect on this production structure. The following years will tell us how the Hungarian economy manages to benefit from the changes that also provide new opportunities. Another question of the future is how the social and regional policy, the R\&D policy, education and the institutional order serving social inclusion will react to the widening regional and social inequalities and the already visible shortcomings of the accumulation of human capital. 


\section{REFERENCES}

Bod PÉTER Ákos (2014): Not customary economic policies [Nem szokványos gazdaságpolitikák]. Budapest: Akadémiai Kiadó.

EC (2018): European Commission: Recommendation on the 2018 National Reform Programme of Hungary. Brussels, 23.5.2018, COM(2018) 416 final, https://ec.europa.eu/info/sites/info/files/2018european-semester-country-specific-recommendation-commission-recommendation-hungaryen.pdf.

North, Douglass C. (1993): Economic Performance through Time (Nobel Prize Lecture). Lecture to the memory of Alfred Nobel, December 9, https://www.nobelprize.org/prizes/economicsciences/1993/north/lecture/.

SACKs, JefFrey: What is to be done? The Economist, Jan 13. 1990.

Williamson, J. (1989): What Washington Means by Policy Reform. In John Williamson (ed., 1990): Latin American Adjustment: How Much Has Happened? Chapter 2, Peterson Institute for International Economic, published April 1990. 